\title{
Relationship of Tooth Color with Skin and Eye Color Based on Gender in Young Indian Adults
}

\author{
Karishma Seth ${ }^{1}$, Pankaj Dhawan ${ }^{2}$, Piyush Tandan ${ }^{3}$
}

\begin{abstract}
Aim: To evaluate the relationship of tooth color with skin color and eye color based on gender in young Indian adults. Materials and methods: Two hundred subjects (100 males and 100 females) in the age range of 20-35 years. Skin color was categorized using skin shade tab (aviance beauty palette); eye color was visually assessed; and $L^{*}, C^{*}$ and $h^{*}$ values of tooth were measured using Vita EasyShade

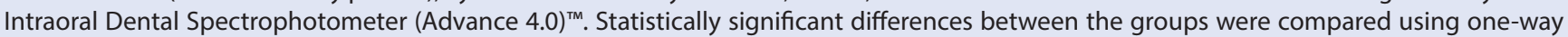
analysis of variance (ANOVA) and Tukey's test. Pearson correlation was used to see the linear relation between the variables.

Results: Significant correlation was observed between skin color and value, eye color and chroma, age, and value in males and females ( $p<0.05$ ). Conclusion: It was concluded that hue, value, and chroma of tooth are partially dependent on skin color, eye color, age, and gender. This study points out that no single parameter should be used while considering the selection of fixed anterior restoration in full-mouth rehabilitation cases as well as for a new set of complete dentures to an edentulous patient, instead various factors need to be kept in mind.

Keywords: Chroma, Eye color, Hue, Intraoral Spectrophotometer, Shade selection, Skin color, Value.

International Journal of Prosthodontics and Restorative Dentistry (2019): 10.5005/jp-journals-10019-1243
\end{abstract}

\section{INTRODUCTION}

Since the face acts like a frame into which the teeth fit, the shade of the teeth should therefore harmonize with the facial color. ${ }^{1}$ Prosthetically speaking, dental beauty is generally considered to be natural or esthetically appropriate when tooth color is in harmony with its vicinity. When providing prosthesis to a dentate patient, the remaining natural dentition are frequently used to select the color of the artificial teeth, but this method cannot be used when providing a long-span anterior fixed partial denture or a new set of complete dentures to an edentulous patient. Since tooth color plays an important role in social attractiveness ${ }^{2}$ and psychological effect, it is imperative that the dentist has the complexion type and age of the patient in mind, so that the operator tests the suggested colors $^{3}$ instead of searching aimlessly through the shade guide, as is generally the custom. Therefore, the most commonly associated features with facial attraction are eyes and skin tone.

Special devices such as spectrophotometer give result in a more objective measurement of color and have shown good repeatability of natural teeth color. ${ }^{4-6}$ Spectrophotometers measure one wavelength at a time from the reflectance or transmittance of an object and have been used to measure the visible spectra of teeth. ${ }^{7}$

The purpose of this study was to relate tooth color with skin color and eye color of a subject and also to evaluate agewise and gender wise the differences that could be seen in relation to the tooth color in young Indian adults.

\section{Materials and Methods}

The study was conducted in the Department of Prosthodontics and Crown and Bridge and Implants, at Manav Rachna Dental College, Faridabad, Haryana, India. A total of 200 subjects (100 males and 100 females) from different geographical areas and in the age group of 20-35 years were assessed for tooth, skin, and eye color. The subjects were randomly selected, thus representing an excellent cross section
${ }^{1-3}$ Department of Prosthodontics and Crowns and Bridges and Implants, Manav Rachna Dental College, Faridabad, Haryana, India

Corresponding Author: Karishma Seth, Department of Prosthodontics and Crowns and Bridges and Implants, Manav Rachna Dental College, Faridabad, Haryana, India, Phone: +91 9599825809, e-mail: drkarishmaseth@gmail.com

How to cite this article: Seth K, Dhawan P, Tandan P. Relationship of Tooth Color with Skin and Eye Color Based on Gender in Young Indian Adults. Int J Prosthodont Restor Dent 2019;9(3):77-81.

Source of support: Nil

Conflict of interest: None

of Indian population. Subjects who were generally healthy individuals having all the maxillary and mandibular anterior teeth with satisfactory oral hygiene and healthy periodontium were included in the study and subjects with restored/ bleached anterior teeth, any tooth development abnormalities, intrinsic/extrinsic staining, eye contact lenses, bleached skin ( $<3$ months) were excluded from the study.

The purpose and procedure of study was explained adequately and an informed consent was obtained from all the subjects. Each subject was made to sit upright on a dental chair, facing the natural daylight and viewed at eye level. Although spectrophotometer functioned independently of external light sources, assessing the skin and eye color required natural daylight. as: ${ }^{8}$

Eye color or iris color was visually inspected and was assessed

\begin{tabular}{ll}
\hline Score & Eye color \\
\hline 1 & Blue, blue/green \\
2 & Brown/gray \\
3 & Dark brown \\
4 & Black \\
\hline
\end{tabular}

(-) The Author(s). 2019 Open Access This article is distributed under the terms of the Creative Commons Attribution 4.0International License (https://creativecommons. org/licenses/by-nc/4.0/), which permits unrestricted use, distribution, and non-commercial reproduction in any medium, provided you give appropriate credit to the original author(s) and the source, provide a link to the Creative Commons license, and indicate if changes were made. The Creative Commons Public Domain Dedication waiver (http://creativecommons.org/publicdomain/zero/1.0/) applies to the data made available in this article, unless otherwise stated. 

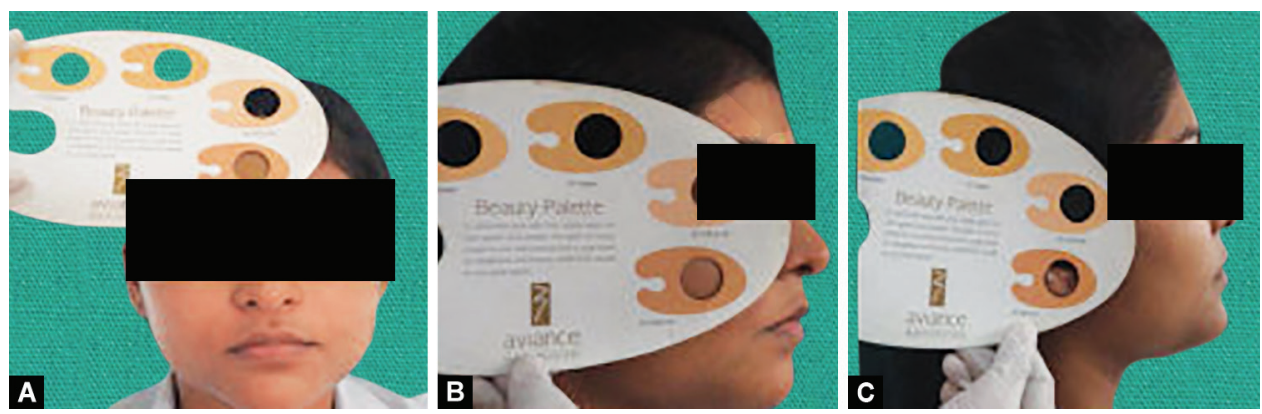

Figs 1 A to C: Subject's skin color being matched with skin shade guide on: (A) Forehead; (B) Malar area; (C) Earlobe
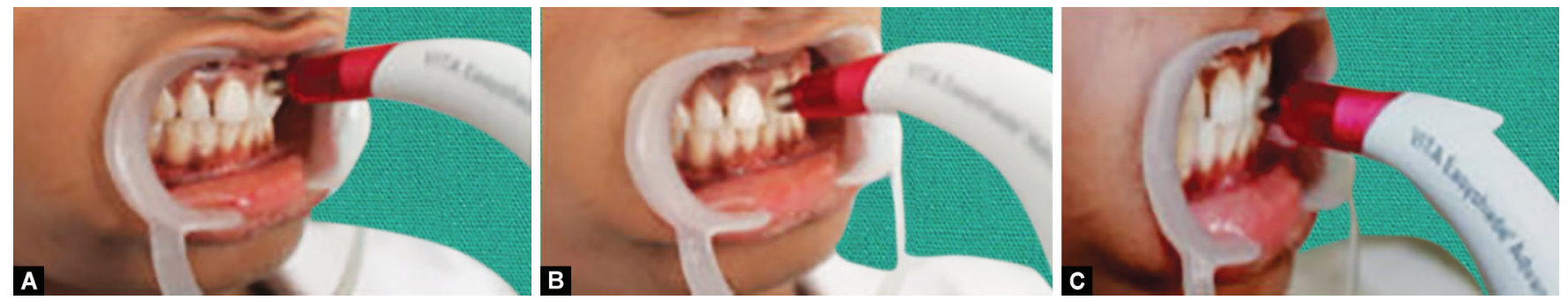

Figs $2 A$ to C: Subject's tooth color being measured using VitaEasy Shade Advance 4.0 at: (A) Cervical third; (B) Middle third; (C) Incisal third

The facial skin was first gently cleaned with a wet cotton pad to remove any dust or makeup. Skin color was determined on three different sites of facial $\operatorname{skin}^{9}$ (Fig. 1), i.e., the forehead at $3 \mathrm{~cm}$ above the nasal bridge, the malar area at the intersection of the ala-tragus line, with a vertical line from outer canthus, and the earlobe in the middle of its outer surface, and then it was categorized using skin shade tab (aviance beauty palette) as:

\begin{tabular}{ll}
\hline Score & Skin shade \\
\hline 1 & Very light \\
2 & Light \\
3 & Middle \\
4 & Dark \\
\hline
\end{tabular}

Tooth color measurements were made after cheek retractor was placed to obtain full exposure of the maxillary central incisors. The instrument was calibrated with the integrated calibration block and then measurement of tooth area's icon was selected.

It was made sure that central incisor is wider than the probe tip and then the tip was placed $2 \mathrm{~mm}$ away from the gingival edge to get the color of cervical area (Fig. 2A). After the indication of two rapid beeps, the probe tip was placed on the middle area (Fig. 2B) and then on the incisal area (Fig. 2C).

To receive extended color information, middle area was selected and expressed on three axes describing the color in threedimensional color space:

$L^{*}$ (value; lightness of color, values from $0=$ black to $100=$ perfect white)

$C^{*}$ (chroma; saturation of color, $0=0 \%$ saturation to $100=$ $100 \%$ saturation)

$h^{*}$ (hue; corresponding to wavelength, commonly called color)

The data obtained were arranged systematically and was transferred to Statistics Package for Social Sciences software version 16.0 for analysis.

\section{Results}

Relationship of skin color, eye color, age, and gender with mean values of $L, C$, and $h$ with their standard deviations are summarized in Table 1. Continuous variables were presented as mean \pm standard deviation. Statistically significant differences between the groups were compared using one-way analysis of variance (ANOVA), and Tukey's honest significant difference post hoc test was applied to confirm where the differences occurred between groups. Unpaired $t$ test was applied to test the difference between mean values in two groups, i.e., male vs female. Pearson correlation was used to see the linear relation between the variables. At $95 \%$ confidence level, $p<0.05$ was considered significant.

The results showed negative and significant correlation between skin color and value ( $L^{*}$ ) (Fig. 3). Chroma and hue showed insignificant correlation with skin color. Negative and significant correlation was seen between eye color and chroma of tooth (Fig. 4) but $L^{*}$ and $h^{*}$ showed insignificant correlation with eye color. A negative but significant correlation was presented between age and value (Fig. 5), whereas $C^{*}$ and $h^{*}$ showed insignificant correlation with age. Males showed lower $L^{*}$ value, higher $C^{*}$ value, and lower $h^{*}$ value compared to females.

\section{Discussion}

The study reported a negative and significant correlation between skin color and value $\left(L^{*}\right)$. This is in accordance with various studies published earlier which concluded that tooth shade is significantly associated with color of the skin, where lighter skin tones have teeth with darker colors (lower $L^{*}$ ) while those with darker skin tones possess teeth of lighter colors (higher $L^{*}$ ). The results of present study also confirmed nonsignificant correlation between skin color and chroma $\left(C^{*}\right)$ and hue $\left(h^{*}\right)$ of tooth. The results are in agreement with that of Jahangiri et al., ${ }^{10}$ Azad et al., ${ }^{11}$ Sharma et al., ${ }^{12}$ and Haralur et al., ${ }^{13}$ who found a negative relationship of skin to teeth color. The methodology in these studies were different as the skin color was evaluated on subject's hand in the study conducted by Jahangiri et al. ${ }^{10} \mathrm{Al}$-Dwairi et al. ${ }^{14}$ concluded in their clinical that there was only moderate agreement between skin and teeth color. Whereas Lagouvardos et al. ${ }^{9}$ found positive but weak correlation between tooth color and skin color. The results are in contrast with those of Hassel et al., ${ }^{8}$ Dummett et al., ${ }^{15}$ Gozalo-Diaz et al.., ${ }^{16}$ and Esan et al. ${ }^{17}$ 
Relationship of Tooth Color with Skin and Eye Color Based on Gender in Young Indian Adults

Table 1: Relationship of skin color, eye color, age, and gender with mean $L^{*}, C^{*}$, and $h^{*}$ values with their standard deviations (SDs) ( $n=$ number of subjects)

\begin{tabular}{|c|c|c|c|c|c|c|}
\hline & \multicolumn{2}{|c|}{$L^{*}$} & \multicolumn{2}{|c|}{$C^{*}$} & \multicolumn{2}{|c|}{$h^{*}$} \\
\hline & Mean & $S D$ & Mean & $S D$ & Mean & $S D$ \\
\hline \multicolumn{7}{|l|}{ Skin color score } \\
\hline $1(n=16)$ & 83.16 & 4.90 & 17.99 & 3.60 & 94.25 & 3.17 \\
\hline $2(n=59)$ & 84.16 & 4.24 & 19.04 & 4.48 & 93.36 & 3.07 \\
\hline $3(n=102)$ & 85.33 & 4.74 & 16.25 & 3.31 & 94.36 & 2.74 \\
\hline $4(n=23)$ & 86.78 & 3.90 & 14.78 & 2.56 & 96.16 & 2.65 \\
\hline \multicolumn{7}{|l|}{ Eye color score } \\
\hline \multicolumn{7}{|l|}{$1(n=0)$} \\
\hline $2(n=62)$ & 83.53 & 4.85 & 19.41 & 5.34 & 94.02 & 3.69 \\
\hline $3(n=110)$ & 84.13 & 4.81 & 17.54 & 3.57 & 93.91 & 2.95 \\
\hline $4(n=28)$ & 84.49 & 4.08 & 16.80 & 2.51 & 94.49 & 2.54 \\
\hline \multicolumn{7}{|l|}{ Age range } \\
\hline $20-23(n=71)$ & 89.04 & 0.97 & 17.22 & 3.14 & 94.33 & 2.74 \\
\hline $24-27(n=51)$ & 84.86 & 1.22 & 17.58 & 3.63 & 94.80 & 3.43 \\
\hline $28-31(n=35)$ & 80.99 & 1.01 & 18.18 & 4.84 & 93.99 & 2.67 \\
\hline $32-35(n=43)$ & 77.09 & 1.05 & 19.73 & 5.26 & 92.64 & 3.38 \\
\hline \multicolumn{7}{|l|}{ Gender } \\
\hline Males $(n=100)$ & 82.68 & 4.54 & 19.10 & 4.66 & 93.57 & 3.24 \\
\hline Females $(n=100)$ & 85.31 & 4.54 & 16.94 & 3.34 & 94.48 & 2.97 \\
\hline
\end{tabular}

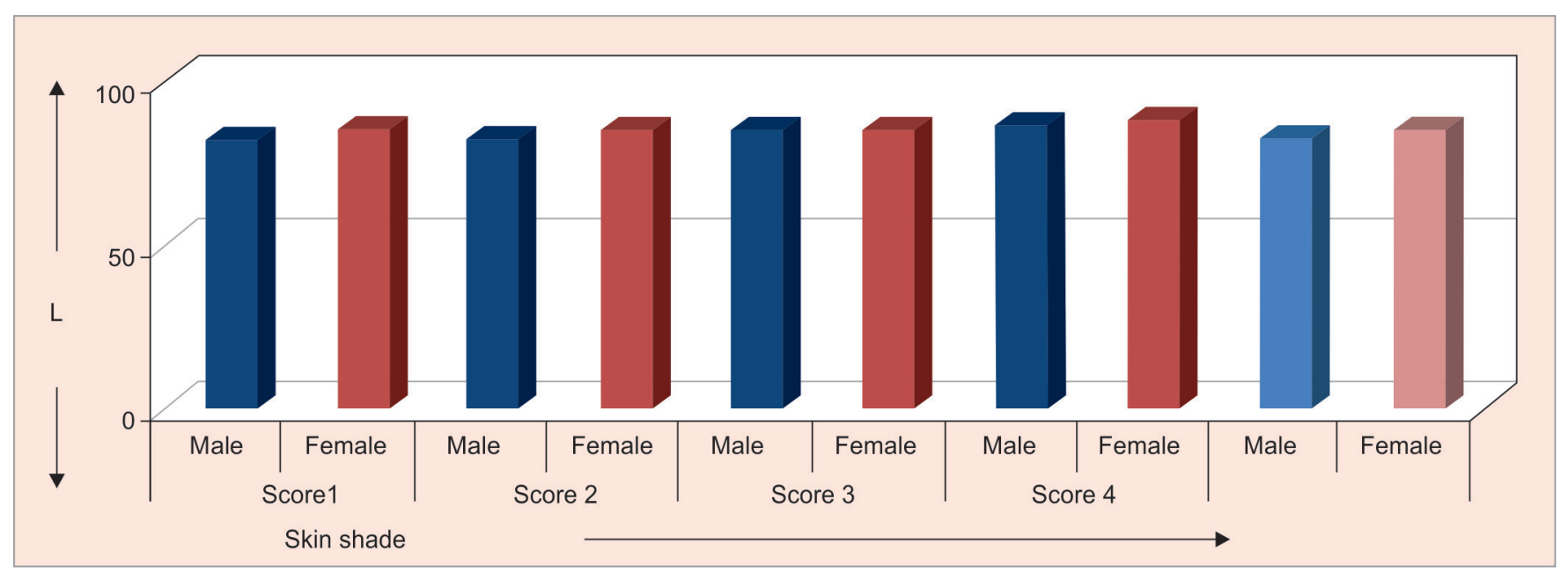

Fig. 3: Negative and significant correlation between skin color and $L^{*}$ in males and females

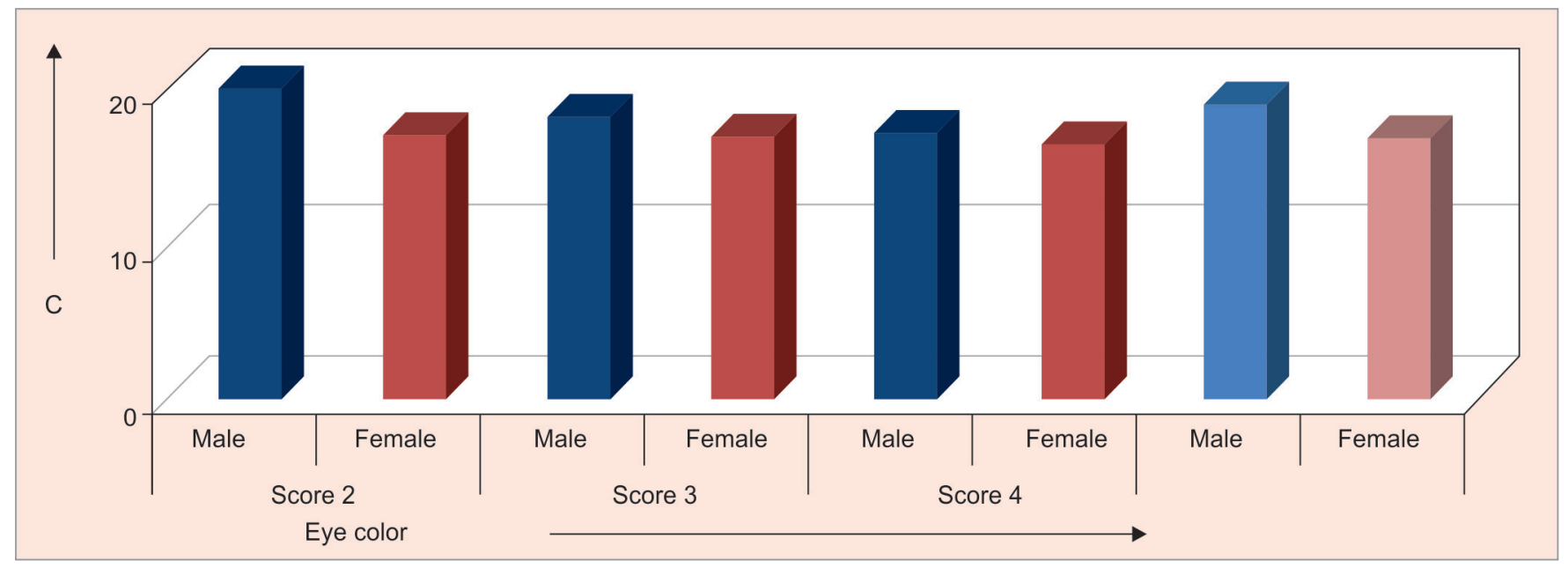

Fig. 4: Negative and significant correlation between eye color and $C^{*}$ in males and females 


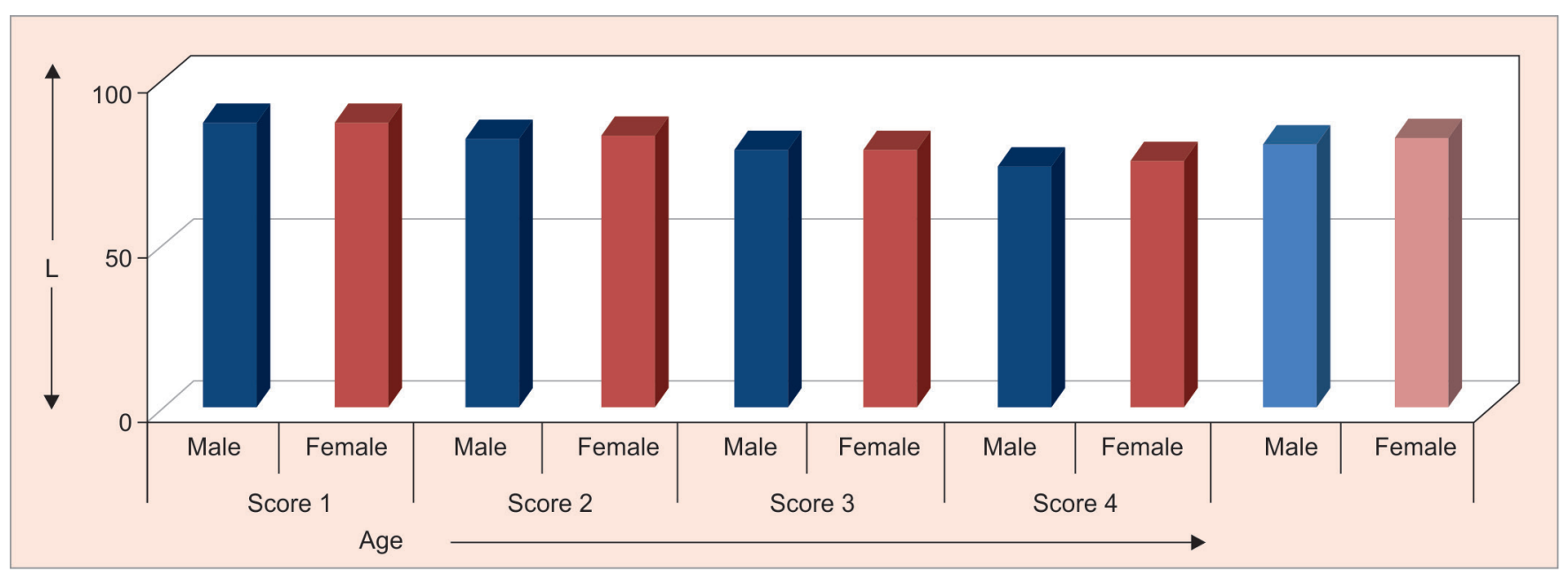

Fig. 5: Negative but significant correlation between age and $L^{*}$ in males and females

who found no relationship of skin to teeth color. However, these differences may be due to population variability.

The second objective of the study was to determine whether correlation existed between tooth color and eye color. Although insignificant relation was observed between eye color and $L^{*}$ and $h^{*}$ of teeth, but a negative and significant relation was seen between eye color and chroma of tooth. Although not many studies have been conducted to determine the relationship between tooth and eye color, but Lagouvardos et al. ${ }^{9}$ in their clinical study stated that no linear relation exists between eye and teeth color. This is partially in accordance with the conclusion of Hassel et al., ${ }^{8}$ who found in a multivariate analysis, that higher $L^{*}$ values of teeth were associated with subjects having lighter eye color. The clinical significance points out that teeth color should not be based on patient's eye color alone. Skin color also has a correlation with eye color but only in populations with dark skin tones, ${ }^{18}$ who tend to have darker eye colors.

The third objective of this study was to determine agewise and gender wise relationship with tooth color. Significant difference was observed between males and females in case of $L^{*}, C^{*}$, and $h^{*}$. Males showed darker teeth compared to females. In present study, males showed darker teeth compared to females. This is in accordance with Hassel et al., ${ }^{8}$ where males have lower $L^{*}$ value, higher (more intense) $C^{*}$ value, and lower $h^{*}$ value as compared to females. In an earlier study conducted by Odioso et al., ${ }^{19}$ it was shown that compared to men, women had statistically lighter and less yellow teeth when tested. According to Jahangiri et al., ${ }^{10}$ no significant difference was observed in tooth color between males and females involving natural teeth.

In the present study, it was found that a negative but significant correlation was observed between age and $L^{*}$ in males and females. A nonsignificant correlation was seen between age and $C^{*}$ and age and $h^{*}$ in males and females. This is in accordance with the studies conducted by Jahangiri et al., ${ }^{10}$ Azad et al., ${ }^{11}$ Esan et al., ${ }^{17}$ and Veeraganta et al., ${ }^{20}$ where it was concluded that older adults are more likely to have darker teeth.

\section{Conclusion}

Within the limitations of the present study, it can be concluded that tooth color is partially dependent on facial characteristics including skin and eye color as well as other characteristics such as age and gender and that no single parameter can be used while considering the selection of fixed anterior teeth restoration as well as for a new set of complete dentures for an edentulous patient. Instead, the opinions and desires of clinician based on clinical judgment should be taken into account to ensure optimal dental esthetics for each individual.

\section{REFERENCES}

1. Sabherwal RS, Gonzalez J, Naini FB. Assessing the influence of skin color and tooth shade value on perceived smile stractiveness. J Am Dent Assoc 2009;140(6):696-705. DOI: 10.14219/jada. archive.2009.0256.

2. Kershaw S, Newton JT, Williams DM. Summary of: the influence of tooth colour on the perceptions of personal characteristics among female dental patients: comparisons of unmodified, decayed and 'whitened' teeth. BDJ 2008;204(5):E9, discussion 256-7. DOI: 10.1038/ bdj.2007.1198.

3. Wright WH. Selection and arrangement of artificial teeth for complete prosthetic dentures. JADA 1936;23(12):2291-2307.

4. Tung FF, Goldstein GR, Jang S, et al. The repeatability of an intraoral dental colorimeter. J Pros Dent 2002;88(6):585-590. DOI: 10.1067/ mpr.2002.129803.

5. Okubo SR, Kanawati A, Richards MW, et al. Evaluation of visual and instrument shade matching. J Prosthet Dent 1998;80(6):642-648. DOI: 10.1016/S0022-3913(98)70049-6.

6. Alshiddi IF, Richards LC. A comparison of conventional visual and spectrophotometric shade taking by trained and untrained dental students. Aust Dent J 2015;60(2):176-181. DOI: 10.1111/adj.12311.

7. Paul S, Peter A, Pietrobon N, et al. Visual and spectrophotometric shade analysis of human teeth. J Dent Res 2002;81(8):578-582. DOI: $10.1177 / 154405910208100815$.

8. Hassel AJ, Doz P. Predicting tooth color from facial features and gender: results from a white elderly cohort. J Prosthet Dent 2008;99(2):101-106. DOI: 10.1016/S0022-3913(08)60025-6.

9. Lagouvardos PE, Tsamali I, Papadopoulou C, et al. Tooth, skin, hair and eye colour interrelationships in greek young adults. Odontology 2013;101(1):75-83. DOI: 10.1007/s10266-012-0058-1.

10. Jahangiri L, Reinhardt SB, Mehra RV, et al. Relationship between tooth shade value and skin color: an observational study. J Prosthet Dent 2002;87(2):149-152. DOI: 10.1067/mpr.2002.121109.

11. Azad AA, Salman A, Majid Z, et al. Relationship of age, gender and skin tone to shades of permanent maxillary central incisors. Pak Oral Dent J 2007;27:119-125.

12. Sharma V,Punia S, Lakshmana B. A study of relationship between skin color and tooth shade value in population of Udaipur, Rajasthan. Int J Dent Clin 2010;2(4):26-29. 
13. Haralur SB, Dibas AM, Almelhi NA, et al. The tooth and skin colour interrelationship across the different ethnic groups. Int J Dent 2014;2014:146028.

14. Al-Dwairi Z, Shaweesh A, Kamkarfar S, et al. Tooth shade measurement and their agreement with skin color. Int J Prosthodont 2014;27(5):458-460. DOI: 10.11607/ijp.3826.

15. Dummett CO, Sakumura JS, Barens $G$. The relationship of facial skin complexion to oral mucosa pigmentation and tooth color. J Prosthet Dent 1980;43:392-396. DOI: 10.1016/0022-3913(80)90207-3.

16. Gozalo-Diaz D, Johnston WM, Wee AG. Estimating the color of maxillary central incisors based on age and gender. J Prosthet Dent 2008;100(2):93-98. DOI: 10.1016/S0022-3913(08)60155-9.
17. Esan $\mathrm{TA}$, Olusile $\mathrm{AO}$, Akeredolu $\mathrm{PA}$, et al. Factors influencing tooth shade selection for completely edentulous patients. J Contemp Dent Pract 2006;7(5):80-87. DOI: 10.5005/jcdp-7-5-80.

18. Spichenok O, Budimlija ZM, Mitchell AA, et al. Prediction of eye and skin color in diverse populations using seven SNPs. Forensic Sci Int Genet 2011;5(5):472-478. DOI: 10.1016/j.fsigen.2010.10.005.

19. Odioso LL, Gibb RD, Gerlach RW. Impact of demographic, behavioural, and dental care utilization parameters on tooth color and personal satisfaction. Compend Contin Educ Dent 2000;21(Suppl 29):S35—S41

20. Veeraganta SK, Savadi CS, Baroudi K, et al. Differences in tooth shade value according to age, gender and skin color. J Indian Prosthodont Soc 2015;15(2):138-141. DOI: 10.4103/0972-4052.155035. 